\title{
NOTE ON BUNSEN'S ICE CALORIMETER
}

BY J. W. MELLOR

The complete separation of dissolved air from the water used in making the "ice kernel" in Bunsen's calorimeter is necessary for accurate results, as was pointed out by Bunsen himself. ${ }^{I}$ At any time the separation of air from water so that the latter will give the characteristic "click" is a difficult mat-

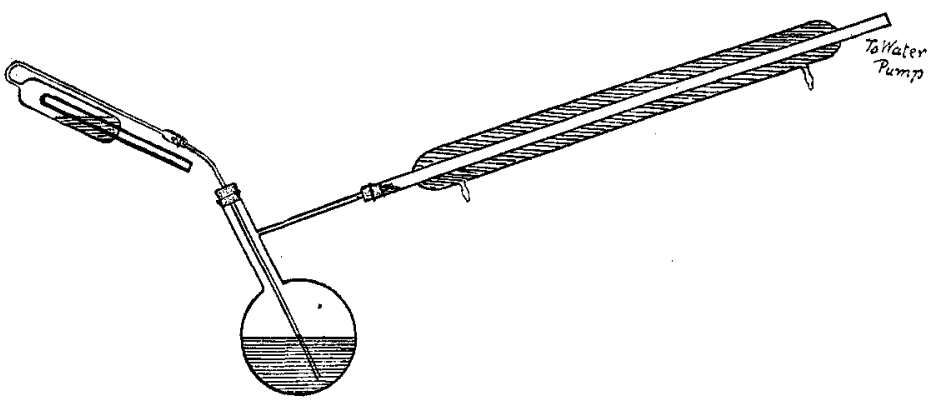

ter, while the filling of the above calorimeter with such water is a still more tedious operation.

The simplification introduced by Wadsworth ${ }^{2}$ gives a fair approximation; while the following simple device requiring little or no attention gives a splendid result.

The end of a Liebig's condenser is fitted to the side neck of an ordinary liter distilling flask, and the other end is connected to a water air-pump. ${ }^{3}$ The flask is about half filled with distilled water, and the outer chamber of the calorimeter is about one-

I Bunsen. Pogg. Ann. I4r, I (1870). Cf. also Schuller and Wartha. Wied. Ann. 2, 359 ( 1877 ).

" Wadsworth. Amer. Jour. Sci. [4] 4, 265 (1897).

${ }^{3} \mathrm{Cf}$. Ostwald. Manual of Physico-Chem. Measurements, I75 (I894). 
third filled with distilled water. A tube dipping almost to the bottom is fitted into the neck of the distilling flask and also into the opening of the side tube of the calorimeter, as shown in the figure.

The pump is set in action, and the water in the calorimeter is heated by a Bunsen flame with a sheet of asbestos placed between the flame and the glass. The flask is heated over a sandbath until its contents give the characteristic "hammering" when shaken. The lamp is then removed from under the calorimeter and the latter will very soon be filled with air-free water. ${ }^{\mathrm{x}}$

The troublesome bumping of water boiling under reduced pressure is considerably mollified by the tube dipping under the water in the flask.

Owens College, Manchester

1 The mercury may be added as recommended by Ostwald, 1. c. 